\title{
Evaluation of Prescribing Appropriateness and Initiatives to Improve Prescribing of Proton Pump Inhibitors at Vancouver General Hospital
}

\author{
Andrea Wan, Katelyn Halpape, Shirin C Talkhi, Claire Dixon, Hafeez Dossa, Jenifer Tabamo, \\ Mark Roberts, and Karen Dahri
}

\begin{abstract}
Background: Proton pump inhibitors (PPIs) have proven clinical efficacy for a variety of indications. However, there is emerging evidence of adverse events associated with their long-term use. The emergence of these adverse events has reinforced the need to regularly evaluate the appropriateness of continuing PPI therapy, and to use only the lowest effective dose for the minimally indicated duration.
\end{abstract}

Objectives: To characterize the appropriateness of PPI orders continued or initiated in the internal medicine and family practice units of Vancouver General Hospital, to detect adverse events associated with PPI use, and to explore the impact of multidisciplinary teaching and provision of educational resources on health care practitioners' views about PPI use.

Methods: A chart review was conducted for patients admitted (for at least 24 hours) between January 1 and December 31, 2015, for whom a hospital formulary PPI was prescribed. An educational initiative, which included interprofessional in-service sessions, a PPI prescribing infographic, a PPI prescribing card, and a patient counselling sheet, was implemented. The impact of these interventions was assessed using a qualitative survey of health care practitioners.

Results: Of the 258 patients whose charts were reviewed, 175 had a PPI prescription before hospital admission, and 83 were initiated on PPI therapy during their hospital stay. Overall, 94 (36\%) of the patients were receiving PPIs without an appropriate indication. Community-acquired pneumonia and Clostridium difficile infections were the most common adverse events potentially associated with PPI use. In-service sessions and educational resources on PPI prescribing were reported to affect the clinical practice of 24 (52\%) of the 46 survey respondents.

Conclusions: The results of this study emphasize the need for ongoing re-evaluation of long-term PPI therapy at the time of admission, during the hospital stay, and upon discharge. Implementing multidisciplinary teaching and providing educational resources may encourage more appropriate prescribing.

\section{RÉSUMÉ}

Contexte : Les inhibiteurs de la pompe à protons (IPP) ont prouvé leur efficacité clinique pour une gamme d'indications. Cependant, de nouvelles données sur leur utilisation à long terme leur imputent des événements indésirables. L'émergence de ces événements indésirables a renforcé l'idée qu'il est nécessaire d'évaluer régulièrement la pertinence d'un traitement prolongé par IPP et d'employer seulement la plus faible dose efficace pendant la durée indiquée la plus courte.

Objectifs : Offrir un portrait de la pertinence des ordonnances d'IPP, renouvelées ou nouvelles, dans les services de médecine interne et de médecine familiale de l'Hôpital général de Vancouver, détecter les événements indésirables liés à l'utilisation des IPP et étudier l'effet qu'ont une formation multidisciplinaire et une fourniture de ressources éducatives sur les points de vue des professionnels de la santé à propos des IPP.

Méthodes : Une analyse rétrospective de dossiers médicaux a été menée auprès de patients qui ont été admis (pendant au moins 24 heures) entre le $1^{\text {er }}$ janvier et le 31 décembre 2015 et qui se sont vu prescrire un IPP inscrit sur la liste des médicaments de l'hôpital. On a mis en place un programme éducatif comprenant des séances de formation interprofessionnelles internes, un document infographique de prescription des IPP, une carte de prescription des IPP et une fiche de conseils aux patients. L'effet de ces interventions a été évalué à l'aide d'une enquête qualitative auprès des professionnels de la santé.

Résultats : Parmi les 258 patients dont le dossier a été examiné, 175 avaient une ordonnance d'IPP avant l'admission à l'hôpital et 83 ont amorcé un traitement par IPP pendant leur séjour. Dans l'ensemble, 94 (36 \%) des patients recevaient un IPP sans indication pertinente. Les infections à Clostridium difficile et les pneumonies extra-hospitalières représentaient les événements indésirables les plus courants potentiellement liés à l'utilisation des IPP. On a signalé que les séances de formation interne et les ressources éducatives sur la prescription des IPP avaient eu un effet sur la pratique clinique de $24(52 \%)$ des 46 participants à l'enquête. 
Keywords: proton pump inhibitors, prescribing initiatives, adverse events

Can J Hosp Pharm. 2018;71(5):308-15
Conclusions : Les résultats de l'étude font ressortir la nécessité d'une réévaluation continuelle des traitements à long terme par IPP au moment de l'admission, pendant le séjour et lors du congé. La mise en place de formation multidisciplinaire et l'offre de ressources éducatives pourraient favoriser des pratiques de prescription plus adéquates.

Mots clés : inhibiteurs de la pompe à protons, programmes de formation sur les pratiques de prescription, événements indésirables

\section{INTRODUCTION}

$\mathrm{P}$ roton pump inhibitors (PPIs) are a class of medications that inhibit parietal cell hydrogen potassium ATPase pumps and suppress gastric acid secretion. Approved indications include severe gastroesophageal reflux disease (GERD), erosive and ulcerative esophagitis, gastric and duodenal ulceration, stress ulcer prophylaxis, prevention of ulceration induced by nonsteroidal anti-inflammatory drugs (NSAIDs), eradication of Helicobacter pylori, Barrett esophagus, and Zollinger-Ellison syndrome. ${ }^{1-4}$ The recommended duration of use is usually short term (2-8 weeks), with few patients requiring long-term treatment. ${ }^{5}$ Despite their capacity to provide clinically significant symptom management, prolonged use of PPIs has been associated with a plethora of adverse effects, including Clostridium difficile infections, hospitaland community-acquired pneumonia, dementia, osteoporosis and fracture, hypomagnesemia, hypoparathyroidism, and vitamin $\mathrm{B}_{12}$ deficiency. ${ }^{1-3,6-13}$ Thus, it may be beneficial to regularly evaluate the appropriateness of PPI use for individual patients, and to treat only with the lowest effective dose for the minimally indicated duration. $^{14}$

According to a 2016 report of the Canadian Institute for Health Information, PPIs accounted for more than $\$ 250$ million dollars of annual spending on prescribed drugs, and ranked ninth among the top 100 drug classes used in British Columbia. ${ }^{15}$ Regionally, this translated to 13174 orders for oral PPIs at Vancouver General Hospital, with 2550 originating from the internal medicine and family practice inpatient units. PPIs are frequently used without a clear indication (e.g., in the absence of ulcer disease, esophagitis, or severe GERD), and inappropriate prescribing has been identified for about $50 \%$ of users. ${ }^{3,16,17}$ In addition, PPI prescriptions are often automatically renewed, despite resolution of the original indication, ${ }^{18}$ a process known as "prescribing inertia". ${ }^{19,20}$ When compounded with their effectiveness in relieving dyspepsia and the lack of immediate adverse effects that would dissuade patients from using these drugs, PPI overprescribing is becoming more prevalent in clinical practice. . $3,317,21,22^{2}$

For these reasons, PPI deprescribing initiatives are increasing, especially for older populations and patients who are taking more than 5 prescription medications daily. ${ }^{18,23}$ At present, interventions to ameliorate PPI overprescribing that have been tried and reported in the literature include standardized guidelines on prescribing practice for patients not receiving PPIs at the time of hospital admission, ${ }^{2}$ PPI deprescribing guidelines for long-term care, ${ }^{8}$ an in-hospital pharmacist-managed program for stress ulcer prophylaxis, ${ }^{24}$ and an in-hospital computerized clinical-decision support intervention. ${ }^{25}$ Common among all of these interventions has been a significant decrease in the average number of PPIs ordered and re-ordered in both inpatient and outpatient settings; however, the overall practice of deprescribing has been difficult to maintain beyond the intervention period. . $2,4,12,25$ Cited barriers have included lack of access to a complete medical history following a transition of care, time limitations in reviewing the complete medical history and reassessing the patient, and malpractice concerns. $8,16,26$

The objective of this study was to first characterize the use of PPIs and detect adverse events associated with PPI use at Vancouver General Hospital, and to then develop, implement, and evaluate an intervention targeted toward improving PPI use.

\section{METHODS}

\section{Phase 1}

In this phase, a retrospective, single-centre study was conducted at a tertiary care teaching hospital located in Vancouver, British Columbia. The hospital pharmacy's computerized prescription database (Carecast patient care information system, IDX Systems Corporation) was used to identify patients who were admitted between January 1 and December 31, 2015, and who received a hospital formulary PPI (pantoprazole or esomeprazole for oral administration) during their admission. Inclusion and exclusion criteria were then applied. Patients had to have stayed in hospital for at least $24 \mathrm{~h}$ and had to have been admitted to one of the internal medicine or family practice units. The following selection process was used for randomization. Charts for eligible patients were numerically labelled; every third chart was selected, and then every sixth chart was removed from those that remained. Finally, a convenience sample of these randomly identified patients was selected for inclusion in the chart review. Baseline 
characteristics, including age, sex, dates of admission and discharge, reason for admission, and medications before admission, were collected. Charts were reviewed to determine the timeframe of the PPI therapy (short-term or long-term). The indication for PPI use was recorded and classified as to appropriateness, according to predetermined criteria (Appendix 1, available at https://www. cjhp-online.ca/index.php/cjhp/issue/view/186/ show $T o c)$. Adverse events potentially related to PPI use were also noted, based on documentation of adverse event criteria (as defined in Appendix 1). Ethics approval was obtained from the University of British Columbia's Clinical Research Ethics Board to conduct the chart review.

\section{Phase 2}

A multidisciplinary intervention targeting improvement in PPI prescribing was developed, based on a literature review and stakeholder input. The multifaceted intervention was implemented between January 23 and March 24, 2017, which represented two 4-week clinical rotations. An infographic directed toward health care professionals, which summarized PPI drug information and tapering regimens, was created (Figure 1). In addition, a PPI prescribing card (Appendix 2, available at https://www.cjhp-online.ca/index.php/cjhp/issue/view/186/ show Toc) was provided to all medical students, medical residents, physicians, and pharmacists in the internal medicine and family practice areas at the start of each rotation. A patient counselling sheet (Appendix 3, available at https://www.cjhp-online.ca/ index.php/cjhp/issue/view/186/showToc), which outlined PPI discontinuation information, was also created; this sheet was provided to the patient during the hospital admission to initiate a discussion about PPI describing and/or to serve as a supplemental reference once PPI de-escalation was initiated. Multidisciplinary in-service sessions were carried out in all targeted units. Some staff members could not attend these sessions in person, so a 7-min online PowerPoint presentation with voiceover was also created, with the link being sent out via e-mail.

A qualitative survey was developed to solicit feedback from the medical, pharmacy, and nursing staff who had been exposed to the intervention; the survey was administered at the end of the data collection period. The survey collected data on awareness of the educational interventions and the impact of these resources on clinical practice, as reported by the participating medical students, medical residents, physicians, nurses, and pharmacists. The utility of the in-service sessions and the infographic, as perceived by the interprofessional team, was also assessed.

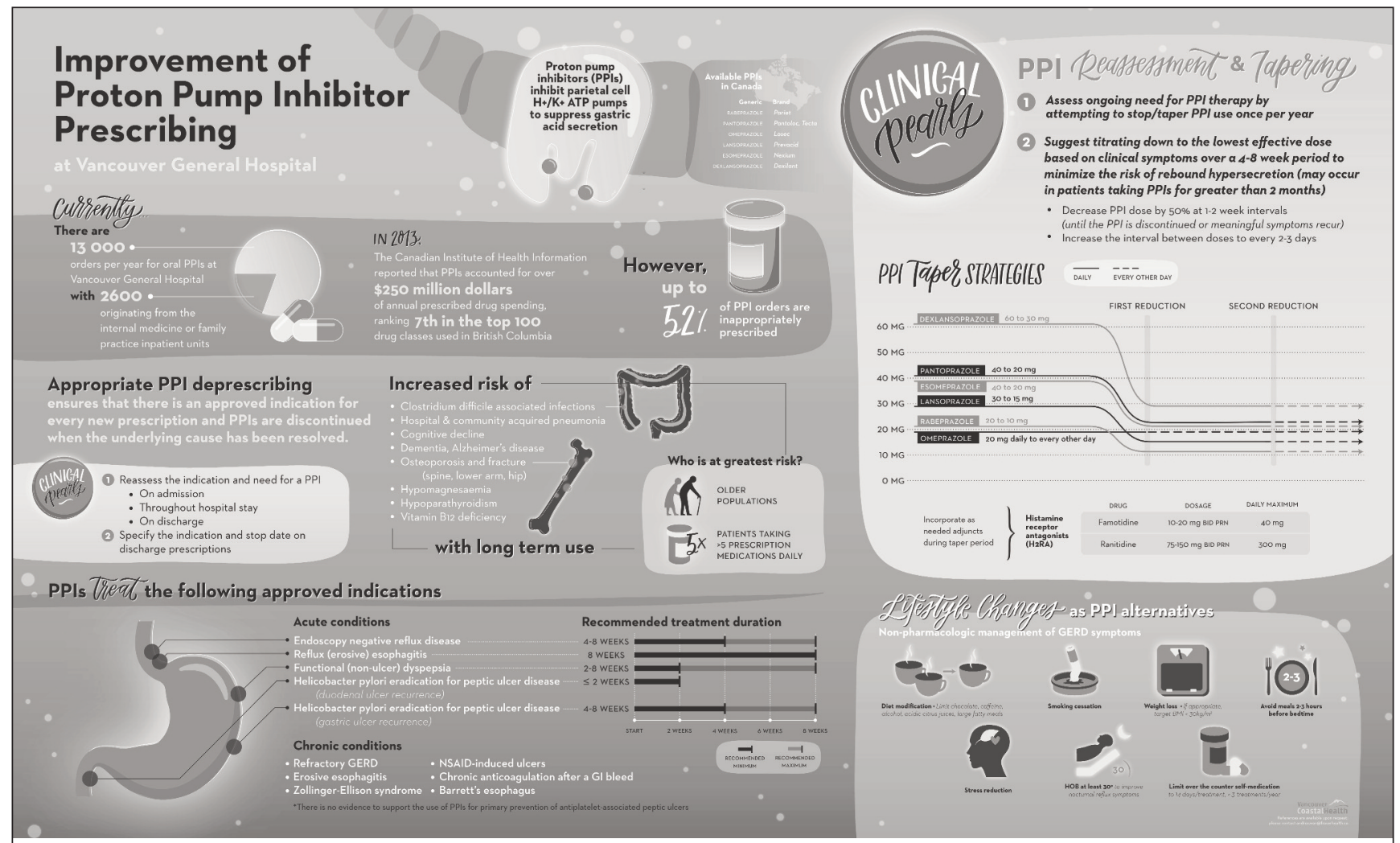

Figure 1. Infographic for prescribing proton pump inhibitors (PPIs). @ ( 2016, Vancouver Coastal Health. Reproduced by permission. 


\section{Statistical Analysis}

Descriptive statistics were used to assess outcomes in relation to the objectives listed above. Results are expressed as means and standard deviations (SDs) (with ranges), medians (with interquartile ranges), or proportions of the total number of patients.

\section{RESULTS}

\section{Phase 1}

A total of 13174 patients were identified as having received a PPI during the study period. Of those, 3969 received treatment on one of the internal medicine or family practice units. After removal of duplicates, 2155 patients met the inclusion criteria, and a convenience sample of 258 charts was reviewed (Figure 2). The mean age of patients included in the chart review was 74 (SD $15)$ years, and $135(52 \%)$ were men (Table 1$)$. The median length of hospital stay was 9 days, with a majority of patients admitted to the internal medicine unit. On average, patients had 5 (SD 2) comorbidities (a majority being of either cardiac or gastrointestinal origin) and were taking 8 (SD 4) medications before hospital admission.

During the hospital stay, 235 (91\%) of the patients received oral pantoprazole, and $23(9 \%)$ received oral esomeprazole (Table 2). For 175 (68\%) of the patients, the PPI orders were for continuation of a PPI initiated before admission, whereas the remaining 83 (32\%) patients had PPI orders initiated during the hospital stay (Table 2). For PPI orders continued in hospital, the median duration of therapy before admission was 18 weeks, with an IQR of 0-31 weeks (Table 2).

Overall, 164 (64\%) of the patients with PPI orders at Vancouver General Hospital had an appropriate indication (Figure 3). The most common indications were history of a bleeding gastrointestinal ulcer or refractory GERD (data not shown). Similarly, 109 (62\%) of the 175 patients with PPIs continued on admission and 55 (66\%) of the 83 with PPIs initiated during the admission had an appropriate indication (Figure 3). Of the 175 patients whose PPI therapy was continued upon hospital admission, 49 experienced adverse events potentially associated with long-term PPI use, with 44 of these 49 patients having taken a PPI for longer than 8 weeks. The most common adverse events were community-acquired pneumonia and $C$. difficile infection (Table 3).

\section{Phase 2}

A total of 46 health care professionals participated in the qualitative survey (Table 4). Given the large number of health care professionals who had rotations in the internal medicine and family practice units, we could not determine the number of staff who were exposed to any aspect of the intervention and hence could not calculate the response rate. Of the 46 survey respon-

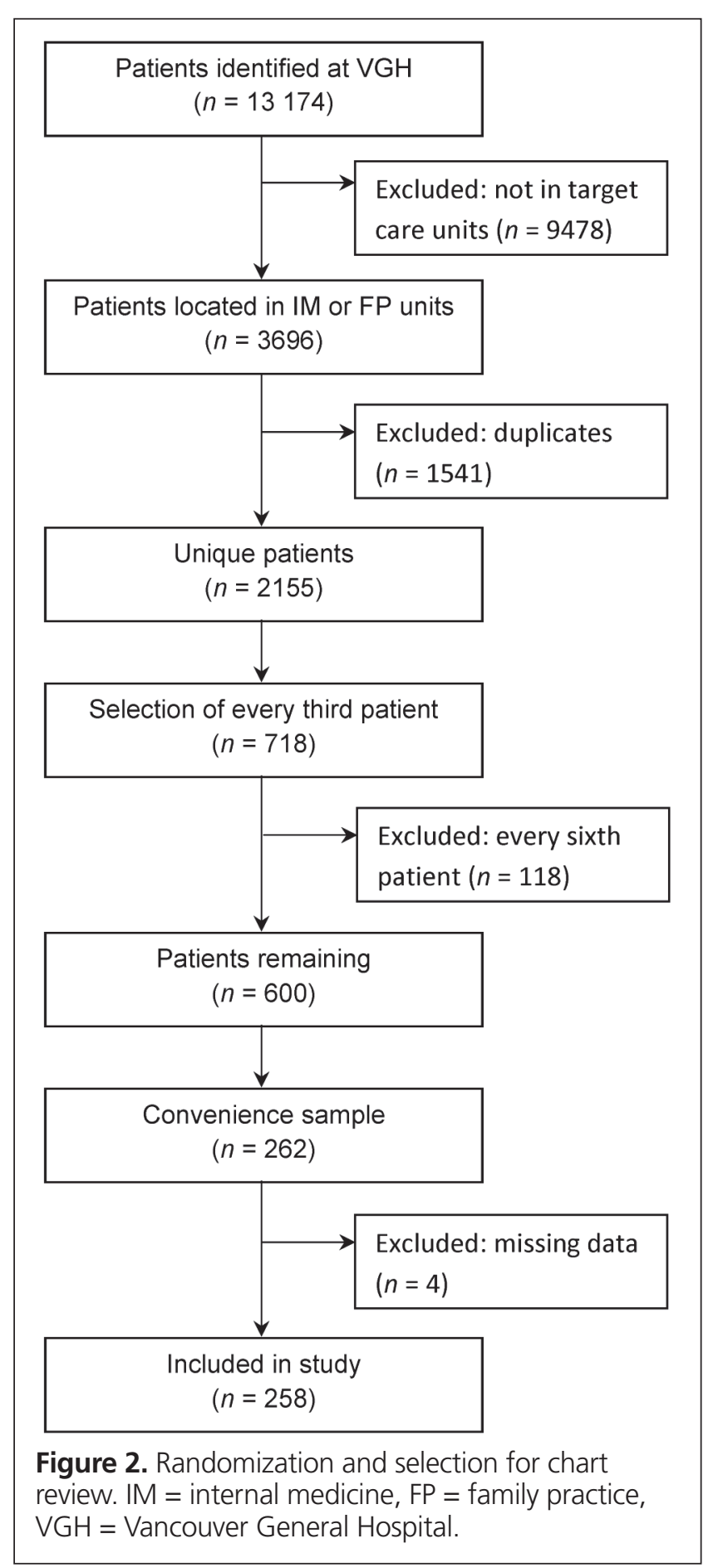

dents, 17 (37\%) reported that they had attended an in-service session or watched the online presentation, and 16 (94\%) of these found it to be an educational and effective use of their time (Figure 4). Of the educational resources available during the 2 months of the intervention, respondents were most aware of the PPI infographic (shown in Figure 1), reporting it to be an effective method of communicating information about appropriate PPI prescribing. Only $7(15 \%)$ and $6(13 \%)$ of survey respondents 
Table 1. Baseline Characteristics of Study Population

\begin{tabular}{|c|c|}
\hline Characteristic & $\begin{array}{l}\text { No. (\%) of Patients* } \\
\quad(n=258)\end{array}$ \\
\hline Age (years), mean \pm SD & $74 \pm 15$ \\
\hline $31-40$ & $9 \quad(3)$ \\
\hline $41-50$ & $13 \quad(5)$ \\
\hline $51-60$ & $28 \quad(11)$ \\
\hline $61-70$ & $36 \quad(14)$ \\
\hline $71-80$ & $61 \quad(24)$ \\
\hline $81-90$ & $84 \quad(33)$ \\
\hline $91-100$ & $26 \quad(10)$ \\
\hline$\geq 101$ & $1(<1)$ \\
\hline \multicolumn{2}{|l|}{ Sex } \\
\hline Men & $135 \quad(52)$ \\
\hline Women & $123 \quad(48)$ \\
\hline \multicolumn{2}{|l|}{ Hospital unit } \\
\hline Internal medicine & $163(63)$ \\
\hline Family practice & $95 \quad(37)$ \\
\hline Length of stay in hospital, median (IQR) & $9(3-19)$ \\
\hline No. of comorbidities, mean \pm SD (range) & $5 \pm 2 \quad(1-10)$ \\
\hline \multicolumn{2}{|l|}{ Type of comorbidity } \\
\hline Cardiac & $227 \quad(88)$ \\
\hline Gastrointestinal & 188 (73) \\
\hline Musculoskeletal & $140 \quad(54)$ \\
\hline Endocrine/metabolic & $128 \quad(50)$ \\
\hline Psychiatric & 126 \\
\hline Respiratory & $105 \quad(41)$ \\
\hline Renal & $83 \quad(32)$ \\
\hline Cancer & $71 \quad(28)$ \\
\hline Genitourinary & $69 \quad(27)$ \\
\hline CNS/neurologic & $61 \quad(24)$ \\
\hline Other & $45 \quad(17)$ \\
\hline Dermatologic & $39 \quad(15)$ \\
\hline $\begin{array}{l}\text { No. of medications before admission, } \\
\text { mean } \pm \text { SD (range) }\end{array}$ & $8 \pm 4 \quad(0-22)$ \\
\hline
\end{tabular}

were aware of the PPI prescribing card and patient counselling sheet, respectively. Overall, 24 (52\%) of the survey respondents felt that the resources provided had had an impact on their clinical practice.
Table 2. Assessment of PPI Orders at Vancouver General Hospital

\begin{tabular}{|c|c|}
\hline Characteristic & $\begin{array}{l}\text { No. (\%) of Patients* } \\
\quad(n=258)\end{array}$ \\
\hline \multicolumn{2}{|l|}{ Timeframe of PPI use } \\
\hline PPI initiated in hospital & $83 \quad(32)$ \\
\hline PPI continued on admission & 175 (68) \\
\hline $\begin{array}{l}\text { Duration of PPI use before admission } \\
\text { (weeks), median (IQR) }\end{array}$ & $18(0-31)$ \\
\hline$\leq 8$ weeks & $63(24)$ \\
\hline 9-52 weeks & 71 (28) \\
\hline$>52$ weeks & 41 (16) \\
\hline \multicolumn{2}{|l|}{ PPI given during hospital stay } \\
\hline Pantoprazole (oral) & $235(91)$ \\
\hline 20 mg once daily & $5 \quad(2)$ \\
\hline $30 \mathrm{mg}$ once daily & $1(<1)$ \\
\hline $40 \mathrm{mg}$ once daily & 181 (77) \\
\hline 40 mg twice daily & $48 \quad(20)$ \\
\hline Esomeprazole (oral) & $23 \quad(9)$ \\
\hline 40 mg once daily & $1 \quad(4)$ \\
\hline 40 mg twice daily & $22(96)$ \\
\hline
\end{tabular}

$\mathrm{IQR}=$ interquartile range, $\mathrm{PPI}=$ proton pump inhibitor.

*Except where indicated otherwise.

\section{DISCUSSION}

Overall, 36\% of patients were taking PPIs that had been ordered without an appropriate indication. More specifically, for $34 \%$ of patients with PPIs initiated during the admission and $38 \%$ of those with continuing PPI therapy (i.e., started before admission), there was no appropriate indication for the PPI order. These findings are similar to the incidence of inappropriate PPI prescribing reported in the literature. $3,16,17,20$ They also illustrate that PPI prescribing at Vancouver General Hospital is vulnerable to "prescribing inertia", a situation in which medications are automatically continued despite resolution of the original indication ${ }^{18}$ and prescribers fail to de-escalate therapy when the therapy is no longer indicated. The observed incidence of inappropriate PPI prescribing may also be secondary to perceived negative consequences if the medication is discontinued, both for the prescriber (diminished credibility and therapeutic relationship with the patient, conflict with other prescribers and health care professionals) and for the patient (need to manage withdrawal

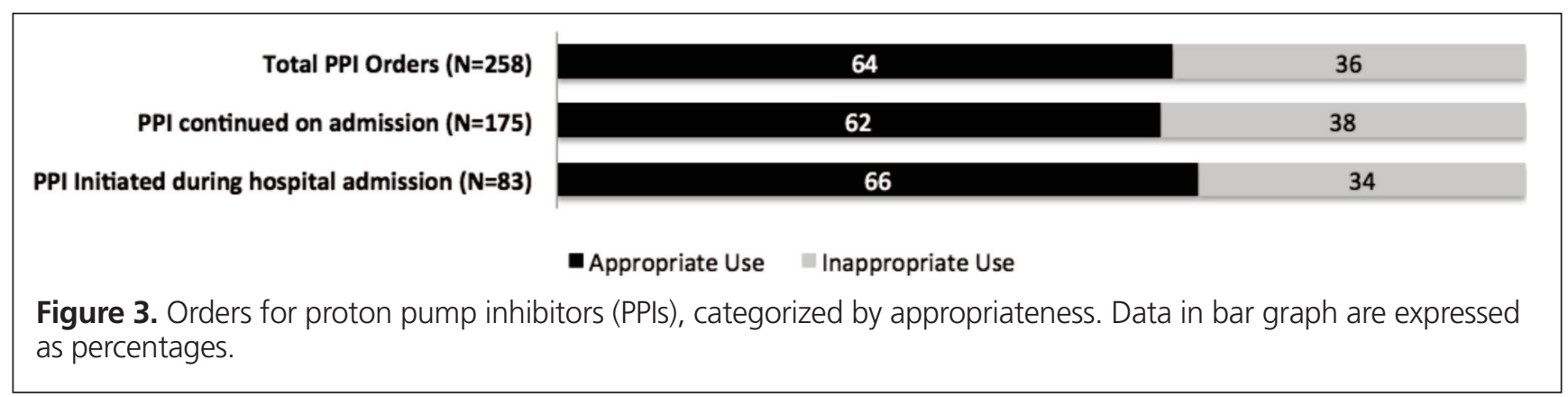


Table 3. Potential Adverse Events Associated with Long-Term PPI Use

\begin{tabular}{|c|c|}
\hline Outcome & $\begin{array}{l}\text { No. }(\%) \text { of Patients } \\
(n=49)^{*}\end{array}$ \\
\hline Clostridium difficile infection & $15 \quad(31)$ \\
\hline Community-acquired pneumonia & $25 \quad(51)$ \\
\hline Fracture & $6(12)$ \\
\hline Vitamin $B_{12}$ deficiency & 3 (6) \\
\hline Other & $3 \quad(6)$ \\
\hline Unknown & 3 (6) \\
\hline
\end{tabular}

*Patients may have experienced multiple adverse effects

Table 4. Professions of Survey Respondents

\begin{tabular}{|c|c|}
\hline Profession & $\begin{array}{l}\text { No. }(\%) \text { of Respondents } \\
(n=46)\end{array}$ \\
\hline Nurse & $22 \quad(48)$ \\
\hline Medical resident & $10 \quad(22)$ \\
\hline Physician & 8 (17) \\
\hline Pharmacist & 3 (7) \\
\hline Medical student & 3 (7) \\
\hline
\end{tabular}

symptoms, symptom relapse, complications, morbidity). ${ }^{19}$ The finding that more than one-third of PPI prescriptions at Vancouver General Hospital were without an appropriate indication supports modification of current practice to favour a more thoughtful and proactive approach to weighing the therapeutic benefits and risks when prescribing PPIs (e.g., lowest effective dose for the minimally indicated duration). ${ }^{14}$

Another important finding of this study was the duration of PPI use for orders continued from before the admission: median 18 weeks, with an IQR of $0-31$ weeks (Table 2). Considering that one-third of all PPI orders were prescribed inappropriately, this result quantifies the potential duration of unnecessary exposure to PPI therapy, especially if the original indication was an acute condition (requiring less than 8 weeks of treatment in total). Also, although a causative relationship between adverse events and long-term PPI use was not elucidated in this study, the association of community-acquired pneumonia and $C$. difficile infections with PPI use corroborates data reported in the literature. ${ }^{3,27-29}$ The combination of these results with the observation that 44 of the 49 patients who experienced an adverse event had been taking a PPI for longer than 8 weeks further reinforces the need to regularly evaluate the appropriateness of continuing this type of medication beyond the recommended short-term duration.

Regarding the educational initiatives used to improve PPI prescribing, $94 \%$ of the 17 survey respondents who attended an in-service session or watched the online video found that this resource was educational and an effective use of their time. In addition, survey respondents were most aware of the PPI infographic as a tool to disseminate information on appropriate PPI prescribing. These findings suggest that accessibility of and exposure to educational resources may have the greatest impact on PPI prescribing practices in the future, and are echoed by the results of similar studies reported elsewhere. For example, the OPTI-SCRIPT study explored this concept in general practitioner practices. ${ }^{30}$ The intervention in that study included having a pharmacist provide a 30-min academic detailing session with the physician to discuss potentially inappropriate prescribing practices, a medication review that detailed web-based pharmaceutical treatment algorithms on alternative pharmacologic and nonpharmacologic treatment options, and patient information leaflets describing the reasons why a medication might not be appropriate and outlining alternative therapies that the physician

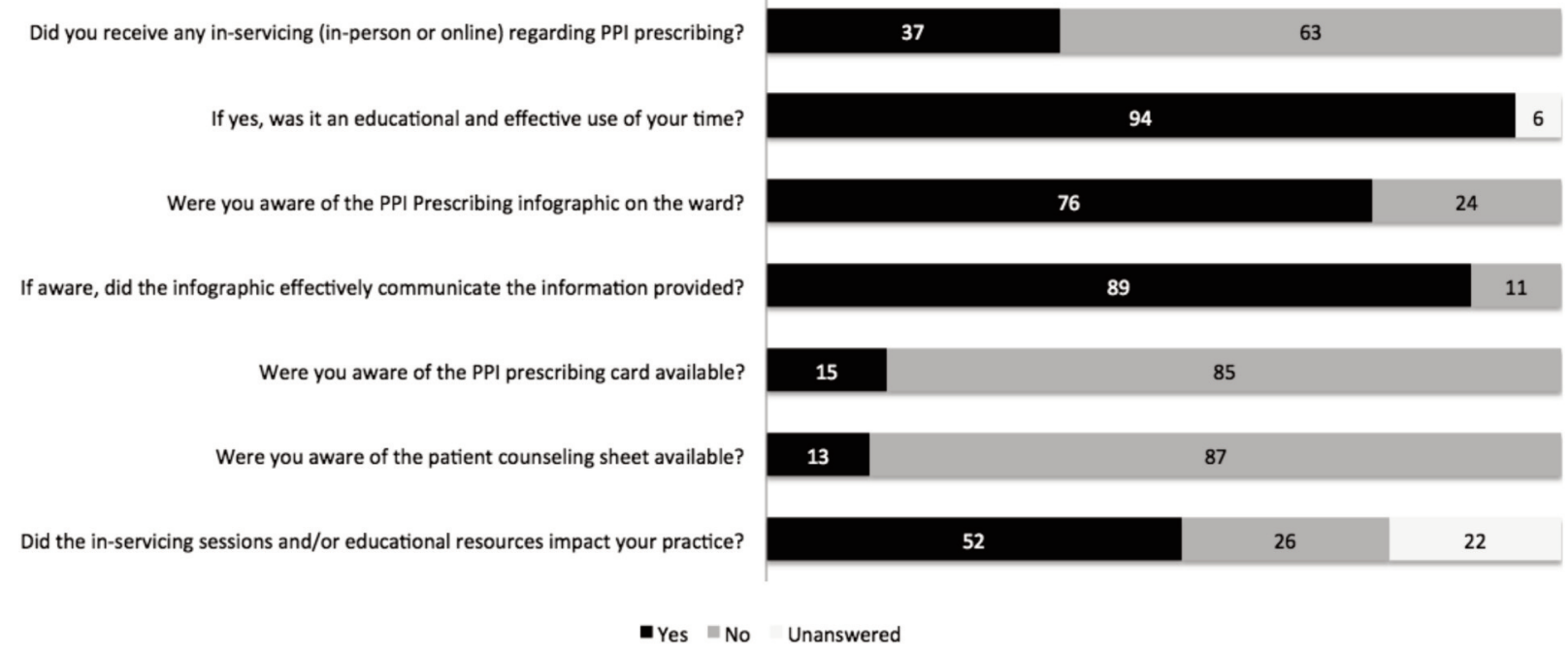

Figure 4. Results of a survey of health care providers. Data in bar graph are expressed as percentages ( $n=46$ respondents). 
could offer. Over a 6-month period, $30 \%$ of inappropriate PPI therapy was stopped or changed to a histamine receptor antagonist, and among the patients who continued to receive treatment, $50 \%$ had a dose reduction. The authors concluded that these initiatives could effectively modify and reduce PPI prescribing. ${ }^{30}$ The academic detailing session and patient information leaflet used in the OPTI-SCRIPT study were similar to our in-service session and educational materials. Given these similarities and the success of the OPTI-SCRIPT study, it can be theorized that had we raised more awareness of the resources available at our site, and continuously advocated for and implemented the algorithms for appropriate prescribing and deprescribing, we could have achieved similar improvements in PPI prescribing.

With more than half of survey respondents reporting that the educational intervention had an impact on their clinical practice, next steps may include continuing to educate the interdisciplinary team to (1) reassess the indication and need for a PPI at the time of admission, throughout the hospital stay, and upon discharge; and (2) specify the indication and stop date for discharge prescriptions (Figure 1). Moreover, early evaluation of PPI therapy may allow time for patient education (Appendix 3) and monitoring of symptom relapse if PPI discontinuation or step-down is initiated during hospital admission, and specifying the indication and stop date on discharge prescriptions may clarify the care plan as the patient transitions from the hospital to the community setting. Where possible, clinical pharmacists could also intervene and provide prescribers with tapering regimens specific to each PPI, as well as making recommendations for adjunctive therapy during the taper period (histamine receptor antagonists, nonpharmacologic management) (Figure 1). Future studies at our site to assess and quantify the effect of these initiatives on PPI prescribing would be beneficial.

\section{Limitations}

The limitations of this study include the small sample size and the descriptive, single-centre, retrospective design. Patient records that did not document the indication for PPI use were excluded, and the results presented may under- or over-estimate the rate of inappropriate PPI prescribing. The duration of PPI use was quantified using the patient's medication reconciliation record or PharmaNet profile (see Appendix 1 for definition), which displayed all medications dispensed to a patient within a 6- or 14-month period before the hospital admission, respectively. Because a majority of patients in the convenience sample had only 1 admission during the study period, and because there was a lack of documentation as to whether the medication reconciliation record or PharmNet profile had been used, delineation of the duration of PPI use beyond 6 months may be biased. Also, because this study endeavoured to detect adverse events with PPI use, we must clarify that the number of adverse events reported is likely an overestimate, given the small sample size, and the adverse events observed may not be secondary to PPI use alone, but rather may have been confounded by other factors (e.g., comorbidities [such as osteoporosis, which may result in bone fractures], disease severity, and medications [such as metformin, which reduces vitamin $B_{12}$ absorption and may potentiate vitamin $\mathrm{B}_{12}$ deficiency]). We were unable to determine the number of staff exposed to any aspect of the intervention and therefore could not determine the survey response rate. This limitation may have introduced selection and participation bias, and the opinions of the 46 survey respondents may not be representative of all individuals exposed to the intervention. Changes in PPI prescribing after the intervention period (e.g., number of appropriate PPI orders, number of PPIs discontinued, dose reductions, change in therapy to a histamine receptor antagonist) were not quantified.

\section{CONCLUSION}

Overall, one-third of patients receiving PPI therapy did not have an appropriate indication. In an era in which patients taking PPIs are of advanced age, have multiple comorbidities, experience substantial pill burden associated with an increasing number of long-term medications, and are at risk of adverse drug reactions, it is important to continue to emphasize appropriate prescribing, documentation of indications for use, and ongoing re-evaluation of long-term PPI therapy. As shown in this study, one approach may be to implement multidisciplinary teaching and provide educational resources. Success in changing practice is well documented, and minimizing exposure to PPI therapy over the long term may positively affect patient outcomes.

\section{References}

1. Gomm W, von Holt K, Thomé F, Broich K, Maier W, Fink A, et al. Association of proton pump inhibitors with risk of dementia: a pharmacoepidemiological claims data analysis. JAMA Neurol. 2016;73(4):410-6.

2. Katz MH. Failing the acid test: benefits of proton pump inhibitors may not justify the risks for many users. Arch Intern Med. 2010;170(9):747-8.

3. George CJ, Korc B, Ross JS. Appropriate proton pump inhibitor use among older adults: a retrospective chart review. Am J Geriatr Pharmacother. 2008;6(5):249-54.

4. Leri F, Ayzenberg M, Voyce SJ, Klein A, Hartz L, Smego RA Jr. Four-year trends of inappropriate proton pump inhibitor use after hospital discharge. South Med J. 2013;106(4):270-3.

5. Kuller LH. Do proton pump inhibitors increase the risk of dementia? JAMA Neurol. 2016;73(4):379-81.

6. Heidelbaugh JJ, Goldberg KL, Inadomi JM. Overutilization of proton pump inhibitors: a review of cost-effectiveness and risk [corrected]. $\mathrm{Am} \mathrm{J}$ Gastroenterol. 2009;104 Suppl 2:S27-32.

7. Proton pump inhibitors in primary care. Victoria (BC): Province of British Columbia, BC Provincial Academic Detailing Service; 2015 [cited 2016 Aug 8]. Available from: https://www2.gov.bc.ca/assets/gov/health/practitioner-pro/ provincial-academic-detailing-service/pad-2015-proton-pump-inhibitorsnewsletter.pdf

8. Thompson W, Hogel M, Li Y, Thavorn K, O’Donnell D, McCarthy L, et al. Effect of a proton pump inhibitor deprescribing guideline on drug usage and costs in long-term care. J Am Med Dir Assoc. 2016;17(7):673 e1-4.

9. Masclee GM, Sturkenboom MC, Kuipers EJ. A benefit-risk assessment of the use of proton pump inhibitors in the elderly. Drugs Aging. 2014; 31(4):263-82. 
10. Kwok CS, Arthur AK, Anibueze CI, Singh S, Cavallazzi R, Loke YK. Risk of Clostridium difficile infection with acid suppressing drugs and antibiotics: meta-analysis. Am J Gastroenterol. 2012;107(7):1011-9.

11. Eom CS, Jeon CY, Lim JW, Cho EG, Park SM, Lee KS. Use of acidsuppressive drugs and risk of pneumonia: a systematic review and metaanalysis. CMAJ. 2011;183(3):310-9.

12. Hamzat H, Sun H, Ford JC, Macleod J, Soiza RL, Mangoni AA. Inappropriate prescribing of proton pump inhibitors in older patients: effects of an educational strategy. Drugs Aging. 2012;29(8):681-90.

13. Benmassaoud A, McDonald EG, Lee TC. Potential harms of proton pump inhibitor therapy: rare adverse effects of commonly used drugs. CMAJ. 2016;188(9):657-62.

14. PPI deprescribing: approaches for stopping or dose reduction of PPIs in those who may not need lifelong treatment. Saskatoon (SK): RxFiles; 2015 [cited 2017 Jan 4]. Available from: http://www.rxfiles.ca/rxfiles/uploads/ documents/PPI-Deprescribing-Newsletter.pdf

15. Prescribed drug spending in Canada, 2016: a focus on public drug programs. Ottawa (ON): Canadian Institute for Health Information; 2016.

16. Reeve E, Andrews JM, Wiese MD, Hendrix I, Roberts MS, Shakib S. Feasibility of a patient-centered deprescribing process to reduce inappropriate use of proton pump inhibitors. Ann Pharmacother. 2015;49(1):29-38.

17. van Vliet EP, Otten HJ, Rudolphus A, Knoester PD, Hoogsteden HC, Kuipers EJ, et al. Inappropriate prescription of proton pump inhibitors on two pulmonary medicine wards. Eur J Gastroenterol Hepatol. 2008; 20(7):608-12

18. Frank C, Weir E. Deprescribing for older patients. CMAJ. 2014;186(18): 1369-76.

19. Anderson K, Stowasser D, Freeman C, Scott I. Prescriber barriers and enablers to minimising potentially inappropriate medications in adults: a systematic review and thematic synthesis. BMJ Open. 2014;4(12):e006544.

20. McDonald EG, Jones J, Green L, Jayaraman D, Lee TC. Reduction of inappropriate exit prescriptions for proton pump inhibitors: a before-after study using education paired with a web-based quality-improvement tool. J Hosp Med. 2015;10(5):281-6.

21. Hood W, McJunkin B, Warnock A, Girme A, Smith N, Robinson B. Proton pump inhibitor prescribing and costs in a large outpatient clinic. $W V M e d$ J. 2014;110(1):16-21

22. Sánchez-Cuén JA, Irineo-Cabrales AB, Bernal-Magaña G, Peraza-Garay FJ. Inadequate prescription of chronic consumption of proton pump inhibitors in a hospital in Mexico. Cross-sectional study. Rev Esp Enferm Dig. 2013; 105(3):131-6.

23. Frank C. Deprescribing: a new word to guide medication review. CMAJ. 2014;186(6):407-8.

24. Buckley MS, Park AS, Anderson CS, Barletta JF, Bikin DS, Gerkin RD, et al. Impact of a clinical pharmacist stress ulcer prophylaxis management program on inappropriate use in hospitalized patients. Am J Med. 2015; 128(8):905-13.

25. Herzig SJ, Guess JR, Feinbloom DB, Adra M, Afonso KA, Howell MD, et al. Improving appropriateness of acid-suppressive medication use via computerized clinical decision support. J Hosp Med. 2015;10(1):41-5.

26. Sirovich BE, Woloshin S, Schwartz LM. Too little? Too much? Primary care physicians' views on US health care: a brief report. Arch Intern Med. 2011; 171(17):1582-5.

27. Dial S, Delaney JA, Barkun AN, Suissa S. Use of gastric acid-suppressive agents and the risk of community-acquired Clostridium difficile-associated disease. JAMA. 2005;294(23):2989-95.
28. Choudhry MN, Soran H, Ziglam HM. Overuse and inappropriate prescribing of proton pump inhibitors in patients with Clostridium difficileassociated disease. QJM. 2008;101(6):445-8.

29. Laheij RJ, Sturkenboom MC, Hassing RJ, Dieleman J, Stricker BH, Jansen JB. Risk of community-acquired pneumonia and use of gastric acidsuppressive drugs. JAMA. 2004;292(16):1955-60.

30. Clyne B, Smith SM, Hughes CM, Boland F, Bradley MC, Cooper JA, et al. Effectiveness of a multifaceted intervention for potentially inappropriate prescribing in older patients in primary care: a cluster-randomized controlled trial (OPTI-SCRIPT Study). Ann Fam Med. 2015;13(6):545-53.

Andrea Wan, BSc(Pharm), ACPR, is with the Department of Pharmacy, St Paul's Hospital, Vancouver, British Columbia.

Katelyn Halpape, BSc(Pharm), ACPR, PharmD, is with the Department of Pharmacy, Vancouver General Hospital, Vancouver, British Columbia.

Shirin C Talkhi, BSc(Pharm), was, at the time of this study, an undergraduate student in the Faculty of Pharmaceutical Sciences, The University of British Columbia, Vancouver, British Columbia.

Claire Dixon, BSc(Pharm), was, at the time of this study, an undergraduate student in the Faculty of Pharmaceutical Sciences, The University of British Columbia, Vancouver, British Columbia.

Hafeez Dossa, BSc(Pharm), was, at the time of this study, an undergraduate student in the Faculty of Pharmaceutical Sciences, The University of British Columbia, Vancouver, British Columbia.

Jenifer Tabamo, RN, is with the Department of Medicine, Vancouver General Hospital, Vancouver, British Columbia.

Mark Roberts, MD, is with the Department of Medicine, Vancouver General Hospital, Vancouver, British Columbia.

Karen Dahri, BSC, BSC(Pharm), ACPR, PharmD, is with the Faculty of Pharmaceutical Sciences, The University of British Columbia, and the Department of Pharmacy, Vancouver General Hospital, Vancouver, British Columbia.

Competing interests: None declared.

\section{Address correspondence to:}

Dr Karen Dahri

Pharmaceutical Sciences

Vancouver General Hospital

855 West 12th Avenue

Vancouver BC V5Z 3N1

e-mail: Karen.Dahri@vch.ca

Funding: Creation of the infographic (Figure 1) was funded by Karen Dahri's start-up research funds from the Faculty of Pharmaceutical Sciences at The University of British Columbia. No other funding received.

Acknowledgement: The authors are indebted to Sarah Kim for the design and illustration of the infographic (Figure 1). 